\title{
Response in a Hot Environment: The Physiological Adaptation of the Sub-elite Para-swimming Athletes
}

\author{
Kunjung Ashadi ${ }^{1, *}$ Imam Kuncoro ${ }^{1,}$ Roy Agustinus Soselisa ${ }^{1,}$ Ribut Budiyono, \\ Laily Mita Andriana ${ }^{1}$, Zusron Hasyim ${ }^{1}$
}

\author{
${ }^{1}$ Faculty of Sport coaching, Universitas Negeri Surabaya Surabaya, Indonesia \\ *Corresponding author. Email: kunjungashadi@unesa.ac.id
}

\begin{abstract}
Thermoregulation is an effort to maintain body temperature within the normal range, it's achieved by maintaining a balance between the heat generated in the body and the heat released. The purpose of this study was to analyze the physiological adaptation response in a hot environment in the sub-elite athlete's paraswimming. The method used is quantitative with pre-test and post-test design, which examines five paraswimming athletes. The data were collected for nine weeks and includes body weight changes, temperature, and relative humidity during exercise. The analysis data used are mean, standard deviation, Wilcoxon test, and Mann-Whitney test. The results of this study are that there is a difference between the training sessions in the morning and the afternoon on the loss of body fluids of para-swimming athletes $(p<0,00)$. The amount of fluid loss in athletes decreased every week $(\mathrm{p}<0,00)$. The temperature and relative humidity in the morning session was higher than in the training session in the afternoon. The decrease in the amount of bodies fluid loss is caused by various factors, including the drinking pattern strategy applied by each athlete and the athlete's body starting to adapt to the conditions of the training environment.
\end{abstract}

Keywords: Body fluid, environment, relative humidity, temperature, thermoregulation

\section{INTRODUCTION}

The training program is made systematically and continuously based on the application of various aspects such as physiological, psychological, and biomechanics, which aims to obtain functional training results (1). The training program has the aim of improving a training effect caused by the adaptation of a given training variable (intensity, frequency, volume, and so on) is the definition of training load (2). Training load is needed to improve positive exercise adaptation and training load can be used to prevent athletes from fatigue, physiological disorders, injuries, and even psychological disorders (3).

The training load monitoring is needed in the training program to get maximum exercise results (4). Physiological markers are measurement parameters for internal training load. These parameters are used to provide an average measure of training carried out over time for monitoring training sessions (5). Measurement of internal training load is recognized as a measuring tool that is valid and reliable (6). Internal training load measurements such as the measurement by using the rate of perceived exertion (RPE), heart rate, hydration status, and so forth (5).

The inhibiting factors for the exercise process in the training environment are very diverse. One of the kinds is environmental factors, namely temperature and relative humidity conditions (7). A hot environment can affect the condition of athletes because a favoured training environment becomes an additional training burden for athletes so that it requires greater energy compared to athletes who train in a comfortable temperature environment (8). Core body temperature is strongly influenced by environmental temperature and exercise intensity also has a direct effect on body temperature, the higher the intensity of the exercise, the taller the increase in body temperature (9).

The consequences that occur if a person exercises in a glorious environment are that it affects the decline in achievement of the sport and can increase the risk of injury caused by hot temperatures (10). These conditions include heat cramps, heat syncope, heat exhaustion, and heat stroke (11). Losing excess body fluids during exercise can lead to dehydration. Dehydration occurs when the body fluid expenditure is greater than intake (12).

Exercise in a hot environment can lead the body to increased stress physiological, and it's can significantly decrease exercise capacity and potentially lead to fatigue, injury, and hyperthermia (13). A previous study by (14) shows that athletes who exercised in hot environmental conditions and 
did not apply good hydration strategies experienced a decrease in exercise performance. The effect of exercise in a hot environment is an increase in skin temperature and core body temperature resulting in decreased exercise performance caused by cardiovascular tension and changes in heart and blood vessel function (15).

Exercising in a hot environment can increase the metabolic rate so that it can increase the accumulation of lactic acid in the blood quickly (1). Therefore, a study by (6) shows that hot environmental conditions are positively related to increased levels of lactic acid. So it can be concluded that environmental conditions have a major impact on a body fluid expenditure so that a hydration strategy must be applied to avoid dehydration (16).

The purpose of this study was to analyze the physiologic adaptation response in a hot environment in the sub-elite athlete's paraswimming. The physiologic adaptation response that is meant is the amount of bodies fluid loss during nine weeks of training. The novelty of this study is to compare two different environmental conditions to the loss of body fluids. This study presented trend line data on body fluid loss during nine weeks of training. This research is expected to be an effort to prevent dehydration and benefit the community and sports players to apply the principles of a good hydration strategy so that the risk factors for injury due to a hot environment can be prevented and minimized.

\section{METHOD}

The method used is quantitative and presented descriptively. The research design used is a pre-test and post-test design which examines five swimming athletes consisting of four male and one female athlete. The age range of the athletes was from 19 years to 33 years. The limited body mass index data is due that the athletes are swimming athletes to the fact who have limitations in their bodies.

The data were collected for nine weeks and includes pre-test weight data before exercise, post-test weight after exercise, temperature, and humidity during exercise. Athletes exercise as much as two training sessions a day, including morning and afternoon sessions. The temperature data and relative humidity data are always measured in each exercise. The loss of body fluid was obtained through the difference in body weight before and after exercise.

This research is non-parametric because of the small size of the sample size used. Therefore, the data analysis techniques used are as follows; mean, standard deviation, Wilcoxon test, and Mann-Whitney test

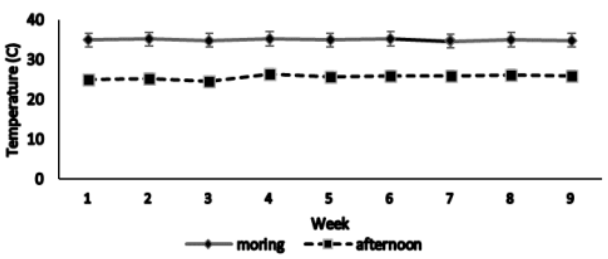

Figure 1. The temperature of the training environment

Based on figure one, it has been explained that the average environmental temperature during exercise changes that are fluctuating. It is known that the highest ambient temperature occurs in the fourth week, $35 \mathrm{c}$ in the morning session and $26 \mathrm{c}$ in the afternoon session. It was explained that training in the morning session had a hotter ambient temperature than the training session in the afternoon.

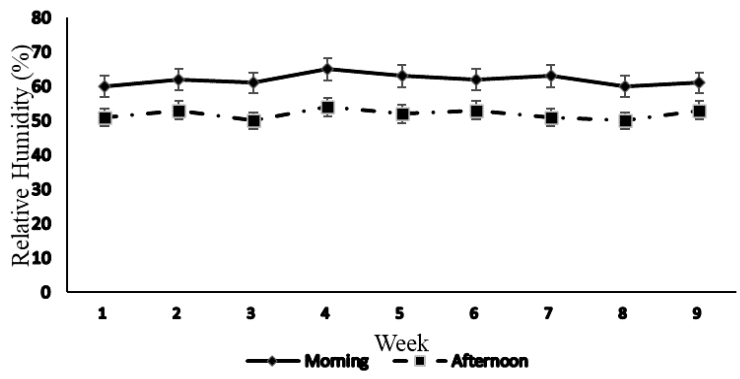

Figure 2. Relative humidity of training environment

Based on Figure 2, it has been explained that the average proportional humidity during exercise changes fluctuates. It is known that the highest relative humidity occurs in the fourth week, which is $65 \%$ in the morning session and $54 \%$ in the afternoon session. It was explained that the training session in the morning had a higher percentage of relative humidity than the training session in the afternoon.

\begin{tabular}{|c|c|c|c|}
\hline & Session & $\begin{array}{c}\text { Mean } \\
\text { Std. } \\
\text { Deviation }\end{array}$ & $\begin{array}{l}\text { Sig. (2- } \\
\text { tailed) }\end{array}$ \\
\hline \multirow[t]{2}{*}{ Temperature } & Morning & $\begin{array}{c}34,8^{\circ} \mathrm{C} \pm \\
0,20\end{array}$ & \multirow[t]{2}{*}{0,000} \\
\hline & afternoon & $\begin{array}{c}25,77^{\circ} \mathrm{C} \\
\pm 0,42\end{array}$ & \\
\hline \multirow[t]{2}{*}{$\begin{array}{l}\text { Relative } \\
\text { humidity }\end{array}$} & Morning & $\begin{array}{c}61,8 \% \pm \\
1,87\end{array}$ & \multirow[t]{2}{*}{0,000} \\
\hline & Afternoon & $\begin{array}{c}51,6 \% \pm \\
1,4\end{array}$ & \\
\hline
\end{tabular}


Tabel 1. The description of temperature and relative humidity of training environment

Based on table 1, it has been explained the average temperature and humidity for nine weeks. The table explains that there are differences in temperature and humidity between the morning and afternoon training sessions. The condition of the exercise environment in the morning has a hotter temperature than the training conditions in the afternoon. The humidity in the morning is higher than the humidity in the afternoon. Based on the web bulb globe temperature index (WBGT), the status of environmental conditions in the morning is categorized as dangerous. In this condition, someone who does intensive exercise without applying a good hydration strategy can experience heat exhaustion. The condition of the training environment in the

Afternoon based on the web bulb globe temperature index has a warning status. Under these conditions, a person who does intensive exercise without applying a good hydration strategy can lead to dehydration and fatigue.

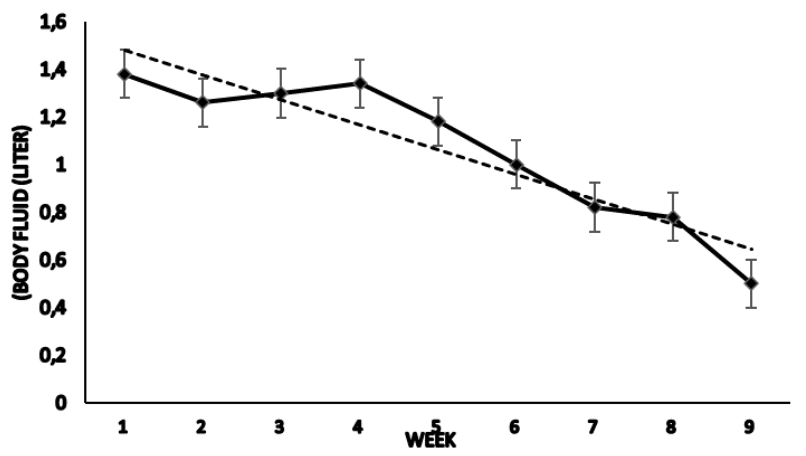

Figure 3. The body fluid loss in the morning session

Based on figure 3, the average fluid loss that occurs in the morning exercise session. Data were collected from the first week of training until the ninth week. Based on the facts during the study, it was shown that athletes did not implement a planned hydration strategy (ad libitum). Based on figure 3 , it is shown that the trend line of the body watery loss during exercise changes. This can be proven by the fact that there is a difference in the average free-flowing loss every week. It has been described that fluid loss increases starting from the second to the fourth week. However, there was a decrease in liquid loss starting from the fifth week to the ninth week so that it can be concluded that the athlete's body began to respond to physiological adaptation but also the athletes did implement a planned hydration strategy.

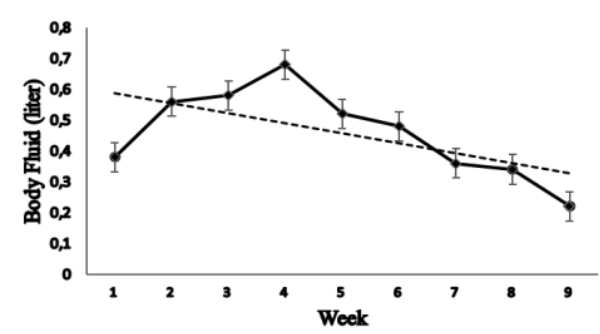

Figure 4 . The body fluid loss in the afternoon session

Based on figure 4 shows the average fluid loss in each week in the afternoon training session. It was explained that the amount of watery loss in athletes decreased every week. This indicates that the athlete's body begins to adapt to the conditions of the training environment. In addition, the trainers provide education about hydration pattern strategies to the athletes. Education on hydration pattern strategies was provided before exercise, during exercise, and after exercise.

Tabel 2. The description and Wilcoxon test of the athlete's body fluid loss which trained in the morning session

\begin{tabular}{|c|c|c|c|}
\hline $\begin{array}{c}\text { Wilcoxon } \\
\text { test }\end{array}$ & $\begin{array}{c}\text { Mean } \\
\text { Std deviation } \\
\text { pre-test }\end{array}$ & $\begin{array}{c}\text { Mean } \\
\text { Std deviation } \\
\text { pre-test }\end{array}$ & Sig. \\
\hline Week 1 & $49.72 \pm 11.01$ & $48.34 \pm 11.02$ & 0,000 \\
\hline Week 2 & $50.16 \pm 11.06$ & $48.90 \pm 11.20$ & 0,000 \\
\hline Week 3 & $50.18 \pm 11.20$ & $48.88 \pm 11.06$ & 0,000 \\
\hline Week 4 & $50.30 \pm 11.50$ & $48.96 \pm 11.55$ & 0,000 \\
\hline Week 5 & $50.34 \pm 11.21$ & $49.16 \pm 11.23$ & 0,000 \\
\hline Week 6 & $50.04 \pm 11.61$ & $49.04 \pm 11.64$ & 0,000 \\
\hline Week 7 & $50.20 \pm 11.36$ & $49.38 \pm 11.52$ & 0,000 \\
\hline Week 8 & $50.32 \pm 11.10$ & $49.54 \pm 11.12$ & 0,000 \\
\hline Week 9 & $50.36 \pm 11.46$ & $49.86 \pm 11.40$ & 0,000 \\
\hline
\end{tabular}

Based on table 2, the description of the body watery loss in para-swimming athletes who are trained in the morning session. liquid loss can be determined by the difference between body weight before exercise and body weight after exercise. Table 2, it is explained that the bodyweight after exercise decreased $(p<0.00)$. It is known that the amount of body fluid excreted in the first week to the fourth week is fluctuating. Meanwhile, from the fifth week to the ninth week of loss of body fluids, there is a decrease. The decrease in the amount of bodies fluid loss is caused by various factors, including the drinking pattern strategy applied by each athlete and the athlete's body starting to adapt to the conditions of the training environment. 
Table 3. The description and Wilcoxon test of the athlete's body fluid loss which trained in the afternoon session

\begin{tabular}{|c|c|c|c|}
\hline $\begin{array}{c}\text { Wilcoxon } \\
\text { test }\end{array}$ & $\begin{array}{c}\text { Mean } \\
\text { Std. } \\
\text { Deviation } \\
\text { pre-test }\end{array}$ & $\begin{array}{c}\text { Mean } \\
\text { Std. } \\
\text { Deviation } \\
\text { post-test }\end{array}$ & Sig. \\
\hline Week 1 & $\begin{array}{c}50.28 \\
\pm 10.86\end{array}$ & $49.90 \pm 10.77$ & 0,012 \\
\hline Week 2 & $\begin{array}{c}50.84 \\
\pm 10.96\end{array}$ & $50.28 \pm 10.93$ & 0,002 \\
\hline Week 3 & $\begin{array}{c}50.96 \\
\pm 11.30\end{array}$ & $50.38 \pm 11.38$ & 0,001 \\
\hline Week 4 & $\begin{array}{c}51.24 \\
\pm 11.32\end{array}$ & $51.92 \pm 11.39$ & 0,000 \\
\hline Week 5 & 51.44 & $51.96 \pm 11.00$ & 0,001 \\
& \pm 11.06 & & 0,001 \\
\hline Week 6 & 51.30 & $51.78 \pm 11.77$ & 0,006 \\
& \pm 11.65 & & 0,007 \\
\hline Week 7 & 51.14 & $51.50 \pm 11.27$ & 0 \\
& \pm 11.26 & & 0,004 \\
\hline Week 8 & 51.20 & $51.54 \pm 11.27$ & 0 \\
\hline Week 9 & 50.60 & $50.82 \pm 11.68$ & \\
& \pm 11.65 & & \\
\hline
\end{tabular}

Based on table three, it has been explained that the bodyweight after exercise decreased $(p<0.00)$. The average body fluid loss that occurs in the afternoon session is less than the fluid loss that occurs in the morning session. This is caused by differences in temperature and relative humidity between the morning and afternoon sessions. The temperature and relative humidity of the air in the morning session was higher than in the training session in the morning.

Tabel 4. The differences of the body fluid loss between morning and afternoon session

\begin{tabular}{|c|c|c|}
\hline $\begin{array}{c}\text { Mann } \\
\text { Whitney } \\
\text { u test }\end{array}$ & $\begin{array}{c}\text { Sig, (2- } \\
\text { tailed) }\end{array}$ & Mean Difference \\
\hline Week 1 & 0,00 & 1,00 liter \\
\hline Week 2 & 0,00 & 0,70 liter \\
\hline Week 3 & 0,00 & 0,72 liter \\
\hline Week 4 & 0,00 & 0,66 liter \\
\hline Week 5 & 0,00 & 0,66 liter \\
\hline Week 6 & 0,00 & 0,52 liter \\
\hline Week 7 & 0,00 & 0,46 liter \\
\hline Week 8 & 0,00 & 0,44 liter \\
\hline Week 9 & 0,00 & 0,28 liter \\
\hline
\end{tabular}

Based on table 4, the different tests are shown between fluid loss that occurs in the training session in the morning session and the afternoon session. Based on the difference test, it is explained that the value of Sig. (2-tailed) of 0.00 it means that there is a difference between the training sessions in the morning and the afternoon on the loss of body fluids of swimming athletes. It was concluded that the amount of body fluid in the morning session was more than the exercise in the afternoon session.

\section{DISCUSSION}

The favoured environment greatly affects the performance and the athlete's body fluid loss after exercising (17). A hot environment can affect the training load performed. A previous study shows that athletes who train in a favored environment can have an impact on the increase in training load (18). In addition, the hot training environment conditions greatly affect the loss of body fluids (19). Based on the data, it showed that the exercise in the morning session lost more body fluids than the exercise in the afternoon session $(p<0.00)$. Environmental conditions in the morning have a hotter temperature and a higher percentage of relative humidity $(p<0.00)$. Based on the web bulb globe temperature index (WBGT), the status of environmental conditions in the morning is categorized as dangerous. An athlete who exercises intensively and does not apply a good hydration strategy is the cause of dehydration conditions to heat exhaustion conditions (20).

A person who loses $2-3 \%$ of body fluids, can lead to a decrease in physical function and harm body temperature regulation during exercise because $70 \%$ of the body consists of fluids (13). Based on these conditions, efforts are needed to meet the body's fluid needs to avoid the effects of dehydration (21). The impact caused by dehydration during exercise is a decrease in the ability of body reactions and concentration, delays in decision making, and an increased risk of sports injury (16). This has been proven by a study that states that 3 $4 \%$ loss of body fluids causes a decrease in power by $3 \%$ (21). A previous study showed that the temperature and relative humidity of the air affects the loss of body fluids (22).

The amount of bodies fluid loss in the first week to the fourth week is more than the fifth week to the ninth week. This is because the athlete's body has not adapted to the conditions of the training environment. In addition, in the first week, the athlete's awareness about the importance of a planned drinking pattern strategy was still considered lacking because the athlete was at the same time applying the ad libitum drinking pattern 
strategy. Hot environmental conditions cause the body to issue a physiological response in the form of sweat released as the body's efforts to achieve homeostasis (23).

Metabolic processes that occur when athletes exercise, cause an increase in body temperature as a burning process and produce energy, and in the burning process, the body sweats as a result of the burning (21). The sweat that comes out of the body caused by sports activities consists of water and electrolytes. A previous study has shown that an athlete who exercised intensively in hot environmental conditions will lose body fluids as much as 0.5 to 1.5 litres/hour (7). Based on research data, it is shown that athletes who train in the morning session in the first week to the fourth week lose more than one litre of body fluid in one training session.

Meanwhile, the amount of bodies fluid loss that occurred in the fifth week to the ninth week gradually decreased $(p<0.00)$. So it can be concluded that the athlete's body begins to adapt to the conditions of the training environment which is called acclimatization (19). Acclimatization of training in a hot environment is an effort of physiological adjustment or adaptation experienced by athletes to a new environment that they will train (24). Heat acclimatization is one method that can be reducing the body's negative biological response to heat stress during exercise (25). Heat acclimatization occurs after going through a process of repeated heat exposure, for example, exercising in hot temperatures (26). The process of heat exposure is expected to occur physiological adaptations in the body to help the lower body temperature in line with an increase in heart stroke volume, sweat rate, and sweat evaporation during exercise (27).

A previous study has shown that it takes about 7-10 days after the heat exposure process begins to activate heat acclimatization (28). The heat exposure process is carried out with a duration of two hours every day during exercise, and the type of exercise used is an aerobic energy system that involves the work of the heart and lungs. The duration and intensity of exercise also need to be increased periodically to make the heat acclimatization process more effective (28). At the beginning of the bodily exercise in hot temperatures, the strain physiologic that occurs is at a fairly high level and is also accompanied by manifestations of an increase in body temperature and heart rate. However, with the same physical/sports training load, the strain physiological will decrease in a matter of days (29). Improvements in heart rate response, body and skin temperature, and sweating rate can be achieved during the first week of a heat acclimatization program (30). According to research, heart rate is the fastest heat acclimatization parameter that decreases, which is around 4-5 days (8). Another study states that the process of adjusting the body's response to heat acclimatization will be achieved within 10 to fourteen days after heat exposure (19). The physiological tolerance process still takes a longer time (32). Another study said that heat acclimatization began to occur after exercise in the third week (28). Heat acclimatization is starting to show results due to an increase in the fitness level of athletes who are long enough training (19).

According to research, it is not only the heart rate that will improve during the heat acclimatization process but several parameters also undergo improvement and adjustment, including reduced core body temperature, improved sweating, improved cardiovascular stability, lower heart rate because athletes are more trained, blood pressure is better maintained. The loss of electrolytes decreases, the blood plasma volume increases. The body's defence against heat becomes better. The tolerance to heat improves, the onset of thermoregulation is faster (28).

Athletes will benefit from heat acclimatization, including fluid balance and hydration mechanisms that will play a role in the work adjustment between thirst stimulation and body fluid needs will be more accurate (26). There is an increase in the capacity of the total amount of body fluids, and blood volume will also increase in the heat acclimatization process (32). However, in the early phase of heat acclimatization, the sweating process will start faster, and this occurs at the beginning of training (24). To maintain the balance of body fluids due to this sweating process, an accurate and optimal hydration strategy is needed (18).

Based on these conditions, a hydration strategy is needed to avoid the effects of dehydration (33). The role of the coach is very much needed in the effort to educate athletes on a good hydration pattern strategy. It is known that coaches provide hydration strategy education to their athletes. Education of hydration pattern strategies was carried out before exercise, during exercise, and after exercise. A study by (34) shows that a planned hydration strategy (planned drink) is better at preventing dehydration than an unplanned hydration strategy (ad libitum drink). In a good training program, hydration strategies are applied during the preparation, competition, and competition training phases, can improve sports performance, reduce the potential for injury due to rising body temperature and increase the speed of body recovery (35). Therefore, a hydration 
regulation or strategy (planned drink) is needed to prevent athletes from becoming dehydrated (12). A good hydration strategy is to consume as much as 400 to $600 \mathrm{ml}$ of water 10 to 15 minutes before engaging in sports activities (36).

\section{CONCLUSION}

Based on the data, it can be concluded that environmental conditions affect the amount of body fluid loss. Hot environmental conditions can increase the amount of body fluid loss. An athlete who trains for the first time in a hot environment will lose excessive body fluids. At the beginning of the physical exercise in hot temperatures, the strain physiological that occurs is at a fairly high level and is also accompanied by manifestations of an increase in body temperature and heart rate. The physiological tolerance process still takes a long time so that the adjustment of the body's response to heat acclimatization will be achieved within a minimum of three weeks. Heat acclimatization is starting to show results due to the increase in the fitness level of athletes who do training for a long time.

\section{ACKNOWLEDGMENT}

The authors would like to thank the Universitas Negeri Surabaya, the National Paralympic Committee of Indonesia (NPCI) East Java Province, and especially para-swimming athletes.

\section{REFERENCES}

[1] Djaoui L, Haddad M, Chamari K, Dellal A. Monitoring Training Load And Fatigue In Soccer Players With Physiological Markers. Physiol Behav [Internet]. 2017;181(July):86-94. Available From: Http://Dx.Doi.Org/10.1016/J.Physbeh.2017 .09 .004

[2] Defreitas V, Nakamura F, Defaria F, Dantas M, Souza N, Buratti J, Et Al. Internal Training Load And Performance Indices Of Cerebral Palsy Football Players And Effects Of One Week With And Without Training On Heart Rate Variability. J Phys Educ Sport. 2020;20(December):3017-22.

[3] Stöggl TL, Reyes PJ, Nieman DC, Collette R, Kellmann M, Ferrauti A, Et Al. Relation Between Training Load And RecoveryStress State In High-Performance Swimming. 2018; Available From: Www.Frontiersin.Org

[4] Mclaren SJ, Macpherson TW, Coutts AJ,
Hurst C, Spears IR, Weston M. The Relationships Between Internal And External Measures Of Training Load And Intensity In Team Sports: A Meta-Analysis. Sport Med [Internet]. 2018;48(3):641-58. Available From: Https://Doi.Org/10.1007/S40279-017-0830Z

[5] Svilar L, Jukić I. Load Monitoring System In Top-Level Basketball Team. Kinesiology. 2018;50(1):25-33.

[6] Reichel T, Boßlau TK, Palmowski J, Eder $\mathrm{K}$, Ringseis R, Mooren FC, Et Al. Reliability And Suitability Of Physiological Exercise Response And Recovery Markers. 2020;10:11924. Available From: Https://Doi.Org/10.1038/S41598-02069280-9

[7] Toomey CM, Mccormack WG, Jakeman P. The Effect Of Hydration Status On The Measurement Of Lean Tissue Mass By Dual-Energy X-Ray Absorptiometry. Eur J Appl Physiol. 2017;117(3):567-74.

[8] Pryor JL, Pryor RR, Vandermark LW, Adams EL, Vanscoy RM, Casa DJ, Et Al. Intermittent Exercise-Heat Exposures And Intense Physical Activity Sustain Heat Acclimation Adaptations. J Sci Med Sport [Internet]. 2019;22(1):117-22. Available From:

Https://Doi.Org/10.1016/J.Jsams.2018.06.0 09

[9] Mitsides N, Cornelis T, Broers NJH, Diederen NMP, Brenchley $\mathrm{P}$, Van Der Sande FM, Et Al. Extracellular Overhydration Linked With Endothelial Dysfunction In The Context Of Inflammation In Haemodialysis Dependent Chronic Kidney Disease. Plos One. 2017;12(8):1-15.

[10] Meade RD, Notley SR, D’Souza AW, Dervis S, Boulay $\mathrm{P}$, Sigal RJ, Et Al. Interactive Effects Of Age And Hydration State On Human Thermoregulatory Function During Exercise In Hot-Dry Conditions. Acta Physiol. 2019;226(1):0-1.

[11] Meade RD, Fujii N, Poirier MP, Boulay P, Sigal RJ, Kenny GP. Oxidative Stress Does Not Influence Local Sweat Rate During High-Intensity Exercise. Exp Physiol. 2018;103(2):172-8.

[12] Hoffman MD, Snipe RMJ, Costa RJS. Ad Libitum Drinking Adequately Supports Hydration During $2 \mathrm{H}$ Of Running In Different Ambient Temperatures. Eur J Appl Physiol [Internet]. 2018;118(12):2687-97. Available From: 
Http://Dx.Doi.Org/10.1007/S00421-0183996-7

[13] Figueroa C, Aguilera A, Hoffmann T, Fukuoka Y. The Relationship Between Perceived Barriers For Physical Activity And Depression In Low Active Community-Dwelling Women. Preprint [Internet]. 2021;1-17. Available From: Https://Doi.Org/10.21203/Rs.3.Rs135211/V1

[14] Machado AF, Evangelista AL, Miranda JM De Q, Teixeira CVLS, Leite G Dos S, Rica RL, Et Al. Sweat Rate Measurements After High Intensity Interval Training Using Body Weight. Rev Bras Med Do Esporte. 2018;24(3):197-201.

[15] Baker LB. Sweating Rate And Sweat Sodium Concentration In Athletes: A Review Of Methodology And Intra/Interindividual Variability. Sport Med. 2017;47(S1):111-28.

[16] Muñoz CX, Johnson EC. Hydration For Athletic Performance. Nutr Enhanc Sport Perform Muscle Build Endur Strength. 2018;533-43.

[17] Belval LN, Hosokawa Y, Casa DJ, Adams WM, Armstrong LE, Baker LB, Et Al. Practical Hydration Solutions For Sports. Nutrients. 2019;11(7).

[18] Krabak BJ, Lipman GS, Waite BL, Rundell SD. Exercise-Associated Hyponatremia, Hypernatremia, And Hydration Status In Multistage Ultramarathons. Wilderness Environ Med [Internet]. 2017;28(4):291-8. Available From: Http://Dx.Doi.Org/10.1016/J.Wem.2017.05 .008

[19] Travers G, Nichols D, Riding N, GonzálezAlonso J, Périard JD. Heat Acclimation With Controlled Heart Rate: Influence Of Hydration Status. Med Sci Sports Exerc. 2020;52(8):1815-24.

[20] Silva RPM, Barros CLM, Mendes TT, Garcia ES, Valenti E, De Abreu LC, Et Al. Correction: The Influence of A Hot Environment On Physiological Stress Responses In Exercise Until Exhaustion (Plos ONE (2019) 14: 2 E0209510 DOI: 10.1371/Journal.Pone.0209510). Plos One. 2019;14(3):1-14.

[21] Baert J, Van Biervliet S, Van Biervliet JP, Vande Walle J, Bentin F, De Graeve L, Et Al. Influence Of Physical Activity On Hydration State In Children With Obesity Before And After A Weight Loss Program. Acta Clin Belgica Int J Clin Lab Med [Internet]. 2019;74(4):236-41. Available
From:

Https://Doi.Org/10.1080/17843286.2018.14 93167

[22] Andriana LM, Ashadi K, Sandi IN. Olahraga Di Lingkungan Indoor Pada Malam Hari Menghasilkan Rasio Keringat Lebih Banyak Dibandingkan Pagi Hari. Sport Fit J. 2019;

[23] Pereira ER, De A'Ndrade MT, Mendes TT, Ramos GP, Maia-Lima A, Melo ES, Et Al. Evaluation Of Hydration Status By Urine, Body Mass Variation And Plasma Parameters During An Official HalfMarathon. J Sports Med Phys Fitness. 2017;57(11):1499-503.

[24] Heathcote SL, Hassmén P, Zhou S, Stevens CJ. Passive Heating: Reviewing Practical Heat Acclimation Strategies For Endurance Athletes. Front Physiol. 2018;9:1-12.

[25] Cyril S, Rob D, Brisswalter C, Jeanick H, Meur Y Le. Optimizing Heat Acclimation For Endurance Athletes: High- Vs LowIntensity Training. Int $\mathrm{J}$ Sports Physiol Perform. 2015;

[26] Karsten B, Baker J, Naclerio F, Klose A, Antonino B, Nimmerichter A. Impairment Of Cycling Capacity In The Heat In WellTrained Endurance Athletes After HighIntensity Short-Term Heat Acclimation. Int J [Internet]. 2017;14(2):156 - 162. Available From: Https:/Www.Cochranelibrary.Com/Central /Doi/10.1002/Central/CN-01787161/Full

[27] Mikkelsen CJ, Junge N, Piil JF, Morris NB, Oberholzer L, Siebenmann C, Et Al. Prolonged Heat Acclimation And Aerobic Performance In Endurance Trained Athletes. Front Physiol. 2019;10(November):1-9.

[28] Racinais S, Périard JD. Benefits Of Heat Re-Acclimation In The Lead-Up To The Tokyo Olympics. $\mathrm{Br} \mathrm{J}$ Sports Med. 2020;54(16):945-6.

[29] Kissling LS, Akerman AP, Cotter JD. HeatInduced Hypervolemia: Does The Mode Of Acclimation Matter And What Are The Implications For Performance At Tokyo 2020? Temperature [Internet]. 2020;7(2):129-48. Available From: Https://Doi.Org/10.1080/23328940.2019.16 53736

[30] Gibson OR, James CA, Mee JA, Willmott AGB, Turner G, Hayes M, Et Al. Heat Alleviation Strategies For Athletic Performance: A Review And Practitioner Guidelines. Temperature [Internet]. 2020;7(1):3-36. Available From: 
Https://Doi.Org/10.1080/23328940.2019.16 66624

[31] Pryor RR, Pryor JL, Vandermark LW, Adams EL, Brodeur RM, Armstrong LE, Et Al. Exacerbated Heat Strain During Consecutive Days Of Repeated Exercise Sessions In Heat. J Sci Med Sport [Internet]. 2019;22(10):1084-9. Available From:

Https://Doi.Org/10.1016/J.Jsams.2019.06.0 03

[32] Ely BR, Blanchard LA, Steele JR, Francisco MA, Cheuvront SN, Minson CT. Physiological Responses To Overdressing And Exercise-Heat Stress In Trained Runners. Med Sci Sports Exerc. 2018;50(6):1285-96.

[33] Giersch GEW, Charkoudian N, Stearns RL, Casa DJ. Fluid Balance And Hydration Considerations For Women: Review And Future Directions. Sport Med [Internet]. 2020;50(2):253-61. Available From: Https://Doi.Org/10.1007/S40279-01901206-6

[34] Febiyanti G, Ashadi K. Erratum: Perbandingan Jenis Pola Minum Terhadap Status Hidrasi Pada Remaja Laki-Laki Dan Perempuan. JUARA J Olahraga. 2020;5(1):114.

[35] Chycki J, Zając T, Maszczyk A, Kurylas A. The Effect Of Mineral-Based Alkaline Water On Hydration Status \& The Metabolic Response To Short-Term Anaerobic Exercise. Biol Sport. 2017;34(3):255-61.

[36] Ganio MS, Armstrong LE, Kavouras SA. Hydration. 2018; 